[Contribution from tha laboratory of Analyticat, Chemistry, Princeton UNIVERSITY.]

\title{
THE REDUCTION OF SOLUTIONS OF FERRIC SALTS WITH MERCURY.
}

By LeRoy W. MCCAy AND WHitam T. ANDERSON, JR.

Received July 22, 1921.

\section{Historical.}

K. Schaffhäut ${ }^{1}$ seems to have first recognized the fact that mercury reduces aqueous solutions of ferric chloride, or more rapidly after the addition of hydrochloric acid, with the formation of ferrous chloride and mercurous chloride. The same observation was made many years later by Carnegie; ${ }^{2}$ and in 1911 Borar $^{3}$ showed the reaction to be so complete that mercury can be used as a reducing agent for ferric compounds in the quantitative estimation of iron.

This method of reducing ferric chloride solutions was observed independently by one of us (M) over a year ago and supposed at the time to be new, for there is not even a reference to it either in the works of Rose and Fresenius, or in the most recent editions of the treatises on volumetric analysis by Classen ${ }^{4}$ and by Beckurts. ${ }^{5}$

Our experience has been that the conclusion arrived at by Borar is correct. His description of the method, however, is unsatisfactorily brief, and since but two quantitative results are given to substantiate his claim, it seemed well to make a detailed study of the reaction, especially as regards its application to the preparation of ferrous chloride solutions prior to titrating them with potassium permanganate or dichromate.

\section{Theoretical.}

When a solution of ferric chloride, containing or not containing free hydrochloric acid, is shaken violently for a few minutes in the presence of metallic mercury, the iron is completely reduced to the ferrous condition, an equivalent amount of mercurous chloride being formed.

$$
2 \mathrm{Hg}+2 \mathrm{FeCl}_{3} \longrightarrow 2 \mathrm{FeCl}_{2}+\mathrm{Hg}_{2} \mathrm{Cl}_{2} \text {. }
$$

The filtrate from the slate-colored mass of finely divided mercury and mercurous chloride gives upon the addition to it of potassium thiocyanate no red color. A solution of ferric sulfate, containing or not containing

1 Schaffhäıt1, Ann., 44, 25 (1842).

2 Carnegie, J. Chem. Soc., 53, 471 (1888).

* Borar, ibid., 99, 1415 (1911).

"Classen, "Theorie t. Praxis der Massanalyse," Akademische Verlagsgesellschaft, Leipzig, 1912.

- Beckurts, "Die Methoden der Massanalyse," Vieweg u. Sohn, Braunschweig. 1913. 
free sulfuric acid, is but partially reduced (at $20^{\circ}$ ) when similarly treated, a state of equilibrium being reached.

$2 \mathrm{Hg}+\mathrm{Fe}_{2}\left(\mathrm{SO}_{4}\right)_{3} \rightleftarrows 2 \mathrm{FeSO}_{4}+\mathrm{Hg}_{2} \mathrm{SO}_{4}$ or $2 \mathrm{Hg}+2 \mathrm{Fe}^{+++} \rightleftharpoons 2 \mathrm{Fe}^{++}+2 \mathrm{Hg}^{+}$.

However, on adding a little hydrochloric acid and again shaking, a complete reduction to the ferrous state is effected. Indeed, a solution of ferric sulfate containing no free hydrochloric acid, but sodium or potassium chloride instead is also completely reduced when shaken violently in the presence of mercury. An amount of sodium chloride equivalent to the quantity of mercurous sulfate formed according to the above equation is sufficient for this purpose.

Although mercurous chloride is an exceedingly insoluble salt, ${ }^{6}$ the liquid after reduction always contains a minute amount of mercury in solution. ${ }^{7}$

$2 \mathrm{HgCl}+2 \mathrm{HCl} \rightarrow \mathrm{H}_{2} \mathrm{HgCl}_{4}+\mathrm{Hg}^{2}$ or, $2 \mathrm{HgCl}+2 \mathrm{Cl}^{-} \rightarrow \mathrm{HgCl}_{4}-+\mathrm{Hg}^{-}$

Its presence is indicated by the black precipitate which appears when a current of hydrogen sulfide is passed into the filtrate. The quantity is so small that thus far we have made no attempt to determine it quantitatively.

In reducing with mercury hydrochloric acid solutions of ferric chloride, containing or not containing sulfuric acid, no especial attention need be paid to the amounts of free acids present, providing of course their concentrations are kept within reasonable limits. If, however, as will be shown later, the Zimmermann-Reinhardt modification of the permanganate method be employed for titrating the ferrous chloride, the 100 to $150 \mathrm{cc}$. of the solution to be reduced should contain not over $10 \mathrm{cc}$. of hydrochloric acid, sp. gr. 1.18-1.19.

The exceedingly small amounts of mercurous chloride and sulfate formed when dil. hydrochloric and sulfuric acids are shaken with mercury for 4 or 5 minutes are due most probably to the presence of atmospheric oxygen. ${ }^{8}$ $2 \mathrm{HCl}+2 \mathrm{Hg}+\mathrm{O} \rightarrow \mathrm{Hg}_{2} \mathrm{Cl}_{2}+\mathrm{H}_{2} \mathrm{O} ; \quad \mathrm{H}_{2} \mathrm{SO}_{4}+2 \mathrm{Hg}+\mathrm{O} \rightarrow \mathrm{Hg}_{2} \mathrm{SO}_{4}+\mathrm{H}_{2} \mathrm{O}$. The reactions proceed slowly, but in the course of several days, or a week, the quantities of mercurous salts formed are relatively large. Their presence has, of course, no bearing on the reduction of the ferric solutions.

\section{Experimental.}

The reductions were made in a long, narrow glass bottle of about 800 cc. capacity, provided with a well-ground neck, and tightly fitting wellground glass stopper. On shaking such a bottle the mercury present is mote readily broken up into tiny globules and the reduction of the ferric 183.

${ }^{B}$ Fresenitus, "Quantitative Analyse," Vieweg u. Sohn, Braunschweig, 1875, 1, p.

7 Ostwald, "Principles of Inorganic Chemistry," Macmillan and Co., New York, 1902, pp. 660, 669 .

${ }^{8}$ Berthelot, Ann. chim. phys., [5] 23, 100 (1881). See also Bailey, J. Chem. Soc., 53,760 (1888). 
salt accelerated. About 20 cc. of redistilled mercury ${ }^{9}(27.0 \mathrm{~g}$.) was placed in the bottle, the ferric chloride solution (100 to $150 \mathrm{cc}$.) containing $10 \mathrm{cc}$. of hydrochloric acid, sp. gr. 1.18-1.19, added, the stopper introduced, and the whole shaken vigorously for from 4 to 5 minutes. We have found that when $0.1400-0.1800 \mathrm{~g}$. of iron is present the reduction is always complete at the end of 5 minutes. The stopper was then removed, washed off into a beaker, the solution along with any suspended mercurous chloride decanted into the same beaker, and the liquid then filtered by suction. The mixture of mercury and mercurous chloride remaining in the bottle was washed by decantation 5 times, $20 \mathrm{cc}$. of water being employed for each washing. All separate wash waters were poured first into the beaker and then through the filter, the final volume of the liquid amounting to about $300 \mathrm{cc}$. Since the mercury in the bottle after a reduction, although mixed with mercurous chloride, is still as active as when first used, we simply stopper the bottle and place it aside so that it may be ready at any moment for further reductions. The mixture of mercurous chloride and finely divided mercury remaining in the beaker and on the filter paper may be preserved and, when a sufficient amount has collected, the mercury may be recovered by covering the mass with a strong solution of stannous chloride, adding hydrochloric acid, and heating for several hours.

In a number of solutions so reduced the iron was determined by the Zimmermann-Reinhardt, ${ }^{10}$ as well as by the Penny ${ }^{10}$ method.

1. The solution consisted of pure crystalline ferric ammonium sulfate, a liter at $20^{\circ}$ containing $14.0765 \mathrm{~g}$. of the salt and $100 \mathrm{cc}$. of hydrochloric acid, sp. gr. 1.18. The strength of the solution was unknown to the experimenter (A.). He used $100 \mathrm{cc}$. for each determination. Using the Zimmerman-Reinhardt method and $0.1 \mathrm{~N}$ potassium permanganate he obtained $0.1627,0.1625,0.1630$, and $0.1627 \mathrm{~g}$. of iron; with the Penny method and $0.1 \mathrm{~N}$ potassium dichromate he obtained $0.1624,0.1627$, $0.1629,0.1631,0.1627$, and $0.1627 \mathrm{~g}$. of iron. The average for the former method is 0.1627 ; for the latter, $0.1627 \mathrm{~g}$. His results agree well with the amount which theory demands, $0.1630 \mathrm{~g}$. The average time necessary to make a determination according to Zimmermann-Reinhardt was 21, according to Penny, 29 minutes. The difference, 8 minutes, is the time required to obtain the end-point on the porcelain spot plate. The average time for filtering and washing combined was 11 minutes. Different analysts require, of course, different intervals of time in which to perform the same operations, still the above will give a fair idea as to the amount of time involved in making a determination, after the substance containing the iron is once in solution.

2. A specimen of finely ground hematite was used. The percentage of iron present was unknown to the experimenter (A.). The ore was dissolved in conc. hydrochloric acid, water added and the small amount of insoluble matter removed by filtration.

The latter was fused with a little sodium carbonate, the melt dissolved in dil.

${ }^{9}$ G. A. Hulett, Phys. Rev., 21, 6 (1905).

10 Treadwell-Hall, "Quantitative Analysis," John Wiley and Sons, New York, 1915, pp. 609 and 641 . 
hydrochloric acid and the solution added to the main portion. The reduction was carried out as already described. By the Z.-R. method 62.92 and $62.90 \%$ of iron were found; by the Penny method 62.94 and $62.94 \%$. The ore had been carefully examined by reducing its sulfuric acid solution with zinc in a Jones reductor, and titrating with potassium permanganate. By this method $62.85 \%$ (av.) of iron was found, as compared with $62.92 \%$ (av.) found by reduction with mercury in hydrochloric acid solution.

3. Magnetite (Sample 29) from the Bureat of Standards was used. The ore was first dried at $100^{\circ}$ to constant weight, and then dissolved in conc. hydrochloric acid exactly as described under (2). In this case also the iron content was unknown to the experimenter (A.). The Z.-R. method gave 55.67, 55.68 and $55.71 \%$ of iron; and the Penny method, 55.72, 55.67,55.64\%; average 55.68\%. According to the Bureat of Standards the ore contains $55.75 \%$ of iron. ${ }^{11}$

Since titanic acid is not reduced by mercury the method may be employed in determining iron in titaniferous ores and minerals. That the presence of titanic acid in the solution introduces no error will be evident from the following results.

TABLE I.

Determination of Iron in the Presence of Titanic Acid.

$\begin{array}{ccc}\begin{array}{c}\text { Fe taken }{ }^{a} \\ \text { G. }\end{array} & \begin{array}{c}\text { TiO }_{2} \text { taken. } \\ \text { G. }\end{array} & \begin{array}{c}\text { Fe found. } \\ \text { G. }\end{array} \\ 0.1416 & 0.0903 & 0.1413 \\ 0.1879 & 0.0087 & 0.1880 \\ 0.1879 & 0.0113 & 0.1877 \\ 0.1517 & 0.0158 & 0.1517\end{array}$

${ }^{a}$ Calculated from amount of crystallized ferric ammonium sulfate weighed out in each case.

The titrations were carried out according to the Z.-R. method.

To get some idea as to the amount of ferric iron reduced by mercury when the solution is a sulfuric acid one, we prepared $500 \mathrm{cc}$. of a solution containing $8.1161 \mathrm{~g}$. of crystalline ferric ammonium sulfate and $25 \mathrm{cc}$. of conc. sulfuric acid. This was poured into a dry bottle containing $20 \mathrm{cc}$. of pure mercury, the bottle was stoppered, shaken violently for 10 minutes, and the whole let stand for 30 minutes. The entire operation was carried out at $20^{\circ}$. Since the supernatant liquid was now perfectly clear, $50 \mathrm{cc}$. was pipetted into a beaker, the mercurous mercury in solution was precipitated with dil. hydrochloric acid as mercurous chloride, this filtered off, and the filtrate titrated with permanganate according to the $\mathrm{Z} .-\mathrm{R}$. method. The removal of the mercurous mercury is imperative, for solittions of mercurous salts reduce permanganate. The bottle and conterits were shaken again at intervals, and after one hour, $50 \mathrm{cc}$. was removed and treated as before. The procedure was repeated, the intervals being lengthened each time.

"2 Dr. Shimer of Easton, Pa., found $55.65 \%$ Fe, 
TABLE II.

Ferric Iron REDUCED by Mercury.

(No chlorides present.)

$\begin{array}{cccc}\text { Expt. } & \begin{array}{c}\text { Elapsed time. } \\ \text { Hours. }\end{array} & \begin{array}{c}\text { Fe(ous) found. } \\ \text { G. }\end{array} & \begin{array}{c}\text { Fe reduced at } 20^{\circ} \\ \% .\end{array} \\ 1 & 0.5 & 0.0499 & 53.22 \\ 2 & 1.5 & 0.0498 & 53.08 \\ 3 & 4 & 0.0499 & 53.22 \\ 4 & 30 & 0.0499 & 53.22 \\ 5 & 148 & 0.0497 & 52.95 \\ 6 & 444 & 0.0499 & 53.22 \\ & & \text { Av. } & 53.15 \%\end{array}$

In the circumstances, then, the state of equilibrium was reached when somewhat over half the iron had been reduced to the ferrous condition.

When a solution of ferrous sulfate containing free sulfuric acid is shaken with mercurous sulfate and mercury a part of the ferrous salt is oxidized to the ferric salt, the following reaction taking place.

$$
2 \mathrm{FeSO}_{4}+\mathrm{Hg}_{2} \mathrm{SO}_{4} \rightleftarrows \mathrm{Fe}_{2}\left(\mathrm{SO}_{4}\right)_{3}+2 \mathrm{Hg} \text {. }
$$

This reaction is, of course, the reverse of the above, but the time required to reach the equilibrium position is in this case considerable. Thus far we have made no attempt to determine the extent of oxidation in any specific case.

That the presence of a very small amount of sodium chloride in a solution of ferric sulfate (even when no free sulfuric acid is present) is sufficient to further a complete reduction of the iron to the ferrous condition when the solution is shaken with mercury will be evident from the following experiment.

$0.5002 \mathrm{~g}$. of ferrous ammonium sulfate $(=0.0712 \mathrm{~g}$. of Fe) and $0.5985 \mathrm{~g}$. of crystallized ferric ammonium alum $(=0.0692 \mathrm{~g}$. of $\mathrm{Fe}$ ) were dissolved in about $100 \mathrm{cc}$. water, exactly $0.0725 \mathrm{~g}$. of sodium chloride (amount equivalent to the mercury oxidized) was added, the solution reduced with mercury, the mercurous chloride filtered off, the filtrate acidified strongly with sulfuric acid, diluted to $250 \mathrm{cc}$, and the iron determined with $0.1 \mathrm{~N}$ potassium dichromate solution. The iron found was $0.1405 \mathrm{~g}$. compared with $0.1404 \mathrm{~g}$. present.

As we have already pointed out, the reaction which takes place when a solution of ferric sulfate is shaken in the presence of mercury may be represented by $2 \mathrm{Hg}+$ $\mathrm{Fe}_{2}\left(\mathrm{SO}_{4}\right)_{3} \rightleftharpoons 2 \mathrm{FeSO}_{4}+\mathrm{Hg}_{2} \mathrm{SO}_{4}$. Since $56 \mathrm{~g}$. of iron is, according to the above equation, equivalent to $200 \mathrm{~g}$. of mercurous mercury, $28 \mathrm{~g}$. of iron is equivalent to $100 \mathrm{~g}$. of mercury which in turn is equivalent to $29.25 \mathrm{~g}$. of sodium chloride. Fifty cc. of $0.1 \mathrm{~N}$ potassium permanganate shows the presence of $0.28 \mathrm{~g}$. of pure iron, and $0.3 \mathrm{~g}$. sodium chloride is a little more than necessary to precipitate the mercury in the mercurous sulfate formed during the complete reduction of the $0.28 \mathrm{~g}$. of iron to the ferrous state. If then we add to a sulfuric acid solution of ferric sulfate, containing not more than 0.28 g. of iron, $0.3 \mathrm{~g}$. of sodium chloride dissolved in a littie water, and shake the solution with mercury, we can, after filtering off the mercurous chloride, dilute the filtrate to $500 \mathrm{cc}$, and without adding the $Z .-R$. mixture proceed at once to titrate with the per. 
manganate. The end-point is sharp, the pink color persisting for at least 5 minutes. The results are very satisfactory as will be evident from those given below.

A solution of crystallized ferric ammonium alum was prepared containing in 250 ce. $12.1813 \mathrm{~g}$. of the salt and $5 \mathrm{cc}$. of conc. sulfuric acid. For each determination $25 \mathrm{cc}$. $=0.1410 \mathrm{~g}$. of $\mathrm{Fe}$ ) was taken, $0.3 \mathrm{~g}$. of sodium chloride added, the solution diluted to $100 \mathrm{cc}$. and the reduction effected with mercury. The filtrate from the mercurous chloride was mixed with more sulfuric acid, diluted to $50^{\circ} \mathrm{cc}$. and titrated at once with permanganate solution. $25 \mathrm{cc}=0.1410 \mathrm{~g}$. Fe. Our analyses showed $0.1411,0.1414,0.1408$ and $0.1412 \mathrm{~g}$. of iron, (av. $0.1411 \mathrm{~g}$ ) as compared with 0.1410 taken.

This method for reducing with mercury solutions of ferric salts is quick, accurate and very convenient. Barring the ordinary reagents and apparatus which are always at hand, only a well stoppered bottle and pure mercury are necessary. The mixture of mercury and mercurous chloride remaining in the bottle may be used over and over again, for after 33 reductions we have found it to be fully as active as was the original pure mercury.

In view of this, as well as of the fact that while zinc reduces titanic acid and mercury does not, the latter metal has an advantage over the former in preparing iron compounds for titration. Moreover, the zinc in a Jones reductor oxidizes rapidly, unless the metal be kept covered with water, and time is required to dissolve out the products of the oxidation with sulfuric acid so that the zinc will function properly. In using stannous chloride a number of details must be carefully observed, and solutions of the salt deteriorate rapidly unless preserved in a non-oxidizing atmosphere. Solutions of ferric salts, containing titanic acid, are frequently reduced at their boiling points with hydrogen sulfide or sulfur dioxide. The procedure is tedious, for to expel the excess of gas continued boiling with subsequent cooling in a current of an indifferent gas is necessary. It is evident also that if the indifferent gas contain traces of air, small amounts of ferrous salt may be reoxidized during the cooling of the solution.

Solutions of potassium ferricyanide, potassium chromate, ammonium molybdate, sodium vanadate, potassium antimoniate, etc., when acidified with hydrochloric acid and shaken with mercury are reduced. Some of these reactions are being investigated.

\section{Summary.}

1. Solutions of ferric chloride, containing or not containing free acid, are rapidly and completely reduced when shaken in the presence of mercury. The same is true of solutions of ferric sulfate, providing a little free hydrochloric acid or alkali chloride be present. Under similar conditions titanic acid is not reduced.

2. A number of determinations of the iron in crystallized ferric ammonium alum, in hematite and in a specimen of magnetite from the Bureau 
of Standards prove that this method of reduction is quick, accurate and most convenient.

3. Some of the advantages of the method over those most commonly employed have been outlined.

4. Mention is made of a number of other substances whose solutions are reduced by mercury.

Princerton, NEW JeRsey.

[CONTRIBUTION FROM THE CHEMTCAL LABORATORY OF THE UNTVERSTTY OF WISCONSIN.]

\title{
THE SEPARATION OF COLUMBIUM AND TANTALUM BY MEANS OF SELENIUM OXYCHLORIDE. ${ }^{1}$
}

\author{
By HeNRy Baldwin MerRiLl.
}

Received July 22, 1921.

It was found by Lenher ${ }^{2}$ that columbium oxide is soluble in a mixture of sulfuric acid and selenium oxychloride, while tantalum oxide is insoluble, or very much less soluble, in the same reagent. This appeared to afford a means of separating the two elements. The purpose of the present investigation was to work out the best experimental conditions for accomplishing the separation.

Previous Methods.-The separation of columbium and tantalum has hitherto been one of the most difficult tasks with which the chemist is confronted. In theit chemical properties, the corresponding compounds of the two elements show hardly any points of divergence which are sharp enough to be used for methods of separation. Of the various methods which have been proposed, only one--the double flutoride method of Marignac ${ }^{3}$-merits any consideration. The Marignac method consists of the crystalli zation of the normal potassium fluotantalate, $\mathrm{K}_{2} \mathrm{TaF}_{7}$, under such conditions of acidity and concentration of potassium fluoride that the columbium will form the more soluble oxyfluoride, $\mathrm{K}_{2} \mathrm{CbOF}_{5}$. The chief advantage of the Marignac method is that the two double fliorides are not isomorphous, and hence no mixed crystals should be obtained. The difference in crystal form affords a convenient means of following the course of the separation. The disadvantages of the method are many and serious. The ratio of the solubility of the columbium compound to that of the tantalum is only about 10 to 1, potassium columbium oxyfluoride being soluble in 12 parts of hot water, and potassium fluotantalate requiring about 1.20 parts. This necessitates many recrystallizations before an approximately complete separation is accomplished, and in no case can all of either constitutent be obtained in a state of purity, since some of each will inevitably remain in the various mother liquors. From the analytical standpoint, this means that the Marignac method cannot be made other than a very rough one. Its limit of error is probably at least $10 \%$. In addition to this inherent error, the method is liable to grave inaccuracies, due to the difficulty in maintaining the concentration of hydro-

${ }^{1}$ Abstract of a portion of a thesis presented to the University of Wisconsin, in partial fulfilment of the requirements for the degree of Doctor of Philosophy, 1921. The work was financed in part by a grant from the University research fund.

${ }^{2}$ Lenher, This Journal, 43, 29 (1921).

${ }^{3}$ Marignac, Ann. chim. phys., [4] 8, 5, 49, 68 (1866). Simpson, Chem. Nerws, 99, 243 (1909), 